\title{
Perceptions and Attitudes about the Concept and Approach of Palliative Care among Carer's and Family Members of Patients on End-of-Life Care: A Cross-sectional Survey
}

Sameena Shah ( $\nabla$ shahsameena4@yahoo.com )

Vancouver Island Health Authority

\section{Faizan Qaisar}

Ali Medicare

Iqbal Azam

Aga Khan University

Khairunnisa Mansoor

Aga Khan University Hospital

\section{Research article}

Keywords: Palliative Care, Carer's, knowledge, Attitudes, Life threatening disease

Posted Date: October 15th, 2019

DOI: https://doi.org/10.21203/rs.2.16031/v1

License: (c) (i) This work is licensed under a Creative Commons Attribution 4.0 International License. Read Full License 


\section{Abstract}

BACKGROUND It is necessary to assess carer's understanding of palliative care. The objectives of this study were to ascertain the attitudes and perceptions about the concept and components of palliative care.

METHODS A cross-sectional survey was conducted. Data was collected from the Aga Khan University Hospital in-patient and out-patient departments and home-based palliative care services from mid 2015 to 2016. All adult care-givers who met the inclusion criteria and gave informed consent were approached by trained data collectors till the sample size was reached.Univariate and multivariable analysis and results were reported as crude prevalence's, crude and adjusted prevalence ratios with 95\% confidence intervals using Cox-proportional hazard algorithm. Mean difference of knowledge and attitude scores by care giver variables was assessed using one-way ANOVA. SPSS version 18 was used and a p-value of less than 5 percent was treated as significant.

RESULTS Out of 250 care givers more than $60 \%$ were 40 years or less and the majority were males. Majority were at least graduates. Approximately $70 \%$ of the respondents agreed with the opinion that the person suffering from cancer should be informed about the diagnosis and disease progression. About forty five percent (95\% C.I.: $39.03 \%, 51.37 \%$ ) of the study respondents had correct knowledge about palliative care. Age and relationship with patient had the most variation in response in terms of significance.

CONCLUSION Young individuals aged $<40$ years, with an education level of matric, children or relations of the patient were found to have significantly more and correct knowledge. The majority believed that the patient should be informed about the diagnosis and that patients should be encouraged to carry out routine activities and be facilitated to fulfill their wishes. Two foundational aspects showed a consistently good understanding and therefore correct knowledge across age groups, gender, education level, and relationship with the patient. Firstly, that palliative care should be offered to everyone suffering from an incurable disease and, secondly, that this approach encompasses not just physical, but also psychological and social needs of the patient, in addition to the needs of the family caring for the patient.

\section{Background}

The World Health Organization (WHO) defines palliative care (PC) as "an approach that improves the quality of life of patients and their families facing the problems associated with life-threatening illness, through the prevention and relief of suffering by means of early identification and impeccable assessment and treatment of pain and other problems, physical, psychosocial and spiritual? ${ }^{(1)}$ Palliative care is a comprehensive patient and family-oriented approach that not only provides care for physical symptoms but also identifies and addresses the psychological, social and spiritual needs of the patient. Furthermore, this approach extends to include the family members not just during the life of the patient, but also after the death of the patient. The palliative care approach, given its holistic nature, is multi-disciplinary and is based on a team that includes physicians, nurses, social workers and other as needed that work with the family member/carer. The team addresses and prioritizes the patient's needs pertaining to physical, emotional, social, and spiritual dimensions of palliative care on a continuum while coordinating this care with all concerned as needed.[2]

By 2020, the WHO estimates that globally, more than 15 million people will experience cancer, and 10 million will die of it each year, which amounts to a $60 \%$ increase in deaths. By 2020, in North America, the number of people who die annually of cancer will increase by $51 \%$ to just fewer than 1 million. An $83 \%$ increase is predicted for South America, a $31 \%$ increase for Western Europe, and a $66 \%$ increase for sub-Saharan Africa and more than $80 \%$ of deaths globally will be in low and middle income countries. ${ }^{(3-4)}$ Palliative care includes the prevention and reduction of suffering by early identification, assessment, and treatment of physical, psychosocial, and spiritual aspects of serious illness and injury. ${ }^{5}$ 
Among several challenges to developing a public health approach, one is the paucity of public awareness of palliative care, as demonstrated by numerous international surveys. ${ }^{6-9}$ In Pakistan, the situation is similar, however, the understanding of the situation is complicated by the lack of baseline data. ${ }^{10,11}$

For any palliative care program to succeed, it should be available to all those who would benefit from it and patients and families should be able to understand the value of this approach in the care of the patient and the family. Lack of knowledge and misconceptions are a barrier to the uptake and meaningful utilization of this comprehensive approach by patients and families, leading to inadequate funding and a dearth of resources. ${ }^{12}$ In Pakistan, there are only a handful of medical institutes offering palliative care formally. ${ }^{13}$ The stress and burden of care of the terminally ill patient is endured by the family members, or informal caregiver/s, who lack training, experience or preparation for this immensely onerous task. This often goes unnoticed and unrecognized increasing stress and fatigue in the carer/s. It is imperative, therefore, to develop educational interventions and tools to enhance the knowledge and skills of family caregivers. ${ }^{13-14)}$ As there is very limited research on PC with family members of the terminally ill in Pakistan, the first step in developing a strategy to support family members while caring for a dying family member and educate them about PC, is to assess their current understanding and attitudes towards this concept of actively caring for a dying relative or person. In this survey, we explored variables regarding the understanding of the principles of PC and attitude towards palliative care among carer's of patients who are near the end of live.

For purposes of clarity we defined the caregiver/s, as a person/s who gives help and protection to someone such as a child, an old person, or someone who is sick. ${ }^{15}$ In our setting, the primary care giver is usually the family member who spends the most time with the patient and is involved in the day to day care of the patient. However, there may be other care givers who would also be in communication with the physicians and nurses and involved in making decisions about patient care.

In the context of palliative care, this would be any individual who spends time with the patient, may be involved in feeding, dressing, or cleaning the patient, giving medicines and making day to day decisions on behalf of the patient. This person may also be involved in discussing patient condition or disease progress with the medical team or distant family members. In our socio-cultural system, this is usually one or more close family member/s like, the spouse, son/s, daughter/s, brother/s and or sister/s. However, occasionally, this individual may be a trained attendant, nurse or nursing assistant.

\section{Methods}

A cross-sectional survey was conducted over a period of one year on two hundred and fifty primary care-giver/s to assess their perceptions and opinions of palliative care and attitudes towards it after obtaining approval from the Ethics Research Committee of the Aga Khan University Hospital (AKUH). The study participants were recruited from the in-patient cancer, neurology, pulmonary and cardiac wards, outpatient consultant clinics, and patient's homes during home visits. The inclusion criteria were any person (female or male) over the age of 18 years who was taking care of a patient diagnosed with a life-threatening disease or condition including cancer, and who conformed to the operational definition of care giver, and who gave informed consent. All care givers who were less than 18 years of age, who refused consent, or did not conform to the operational definition of the primary care giver/s were excluded from the sample. A specially designed pretested self-administered paper questionnaire in Urdu and English, divided into sections was used for data collection and consisted of questions related to the assessment of perceptions in terms of opinions and attitudes of formal caregivers towards palliative care. The questions covered demographic and social aspects like age, gender, educational qualifications, and relationship with the patient. All study participants were approached by the nursing staff or the homebased family physician in the selected study sites; all those who met the inclusion criteria and gave informed consent were 
given the questionnaire till the sample size was reached. The confidentiality of the participants was ensured, and all the data was collected anonymously with access to the principal investigator only.

\section{Data Analysis}

The data was double entered by two data entry operators in Epidata, then verified for data entry errors and cleaned. The cleaned data was then converted into SPSS for analysis. Frequency distributions of care takers' age, gender, level of education, relationship with the patient, opinion about whether the person receiving palliative care should be allowed to carry out normal routine activities or to fulfill all his/her wishes and whether a person should be given a diagnosis of cancer or disease progression were generated. Prevalence with $95 \%$ confidence interval for knowledge of palliative care was also calculated. The association of knowledge of palliative care with care taker's age, gender, level of education and relationship with the patient was assessed using univariate and multivariable analysis and results were reported as crude prevalence's, crude and adjusted prevalence ratios with 95\% confidence intervals using Cox-proportional hazard algorithm.

Each question related to opinion and attitude was given a score of 1 when positive otherwise a score of zero was given. These scores were then aggregated to obtain final correct knowledge and attitude scores for different aspects of PC, including 'goals of PC' score, 'focus of PC' score, 'composition of PC team' score, 'setting of PC' score, 'knowledge about hospice' score, opinion about 'provider of PC' score, opinion about needs of patients suffering from a terminal disease or incurable disease' score, opinion about whether PC should be offered to people diagnosed with a terminal or incurable disease score, opinion about 'the best setting to provide PC' score and opinion about 'the best source for obtaining knowledge about PC' score. Mean difference of these scores by primary care giver's age group, gender, education level and relationship with the patient was assessed using one-way ANOVA. SPSS version 18 was used to analyze the data. A pvalue of less than 5 percent was treated as significant.

\section{Results}

A total of 250 primary care givers were interviewed. More than $60 \%$ of them were 40 years of age or less and the majority were males. More than $85 \%$ of them were at least graduates. More than $50 \%$ of the carers were first degree relatives, like spouse, or a child. About forty five percent (95\% C. $1 .: 39.03 \%, 51.37 \%)$ of the study respondents had correct knowledge about palliative care. Young individuals aged $<40$ years, with an education level of matric, children or relations of the patient were found to have significantly more knowledge about palliative care than their counterparts caring for the patient. (Table 1)

More than half of them agreed that the person receiving palliative care should be allowed to carry out normal routine activities or to fulfill all his/her wishes. Approximately $70 \%$ of the respondents agreed with the opinion attitude/view that the person suffering from cancer should be informed about the diagnosis and disease progression. (Table 2)

Differences in the mean scores of knowledge of different aspects of palliative care by age, gender, level of education and relationship with the patient were observed. (Table 3)

Goals of PC Score ( $F=13.23 ; d f=3,246 ; p$-value $<0.001)$, Focus of PC Score $(F=17.50 ; d f=3,246 ; p$-value $<0.001)$, Team Members of PC Score ( $F=31.08 ; d f=3,246 ; p$-value<0.001), Setting of PC Score $(F=18.15 ; d f=3,246 ; p$-value<0.001), Hospice Knowledge Score ( $F=4.58$; df = 3,246; $p$-value<0.001), Opinion about Provider of PC Score $(F=13.65 ; d f=3,246$; p-value<0.001), Opinion that Palliative Care should be Offered to Everyone Suffering from an Incurable Disease Score $(F=$ 33.16; $d f=3,246 ; p$-value<0.001), Opinion about best setting to provide $P C$ Score $(F=14.64 ; d f=3,246 ; p$-value $<0.001)$ and opinion about the best source of knowledge about PC Score ( $F=4.89 ; \mathrm{df}=3,246$; $p$-value $=0.003)$ were found significantly different by age of the respondent except opinion about the Needs of Patients Suffering from an incurable Disease Score $(F=0.233 ; d f=3,246 ; p-v a l u e=0.873)$. 
Focus of PC Score ( $F=17.02 ; d f=1,248 ; p$-value<0.001), Setting of PC Score $(F=7.002 ; d f=1,248 ; p$-value $=0.009)$, Hospice Knowledge Score $(F=5.12 ; d f=1,248 ; p$-value = 0.025), Opinion about Provider of PC Score $(F=53.94 ; d f=1,248$; p-value<0.001), Opinion about the Needs of Patients Suffering from an Incurable Disease Score $(F=28.02 ; d f=1,248 ; p$ value<0.001), Opinion Patient best setting to provide PC Score $(F=3.93 ; \mathrm{df}=1,248$; $\mathrm{p}$-value $=0.049)$ and Opinion about the best source of providing knowledge about PC Score $(F=11.09 ; d f=1,248 ; p$-value $=0.001)$ were found significantly different by gender of the respondent except Goals of PC Score ( $F=1.177 ; \mathrm{df}=1,248 ; \mathrm{p}$-value $=0.279)$, Team Members of PC Score $(F=3.55 ; d f=1,248 ; p$-value $=0.061)$ and Opinion that Palliative Care should be Offered to Everyone Suffering from an Incurable Disease Score $(F=1.69 ; \mathrm{df}=1,248 ; \mathrm{p}$-value $=0.195)$.

Goals of PC Score ( $F=8.80 ; d f=2,247 ; p$-value<0.001), Focus of PC Score ( $F=73.13 ; d f=2,247 ; p$-value<0.001), Team Members of PC Score ( $F=8.03 ; d f=2,247$; $p$-value<0.001), Hospice Knowledge Score $(F=13.42 ; d f=2,247 ; p$ value<0.001), Opinion about Provider of PC Score ( $F=22.43$; $d f=2,247$; $p$-value<0.001), Opinion about the Needs of Patients Suffering from an Incurable Disease Score ( $F=33.24 ; \mathrm{df}=2,247$; $p$-value<0.001), Opinion that Palliative Care should be Offered to Everyone Suffering from an Incurable Disease Score ( $F=18.25 ; \mathrm{df}=2,247$; $\mathrm{p}$-value<0.001), Opinion of Patient best setting to provide PC Score $(F=11.47$; $d f=2,247$; $p$-value $<0.001)$ and Opinion about the best source of providing knowledge about PC Score $(F=4.13$; $d f=2,247$; $p$-value $=0.017)$ were found significantly different by level of education except Setting of PC Score $(F=2.01 ; d f=2,247 ; p$-value $=0.136)$.

Goals of PC Score $(F=7.25 ; d f=2,247 ; p$-value = 0.001), Focus of PC Score $(F=22.53 ; d f=2,247 ; p$-value<0.001), Setting of PC Score ( $F=17.18$; $d f=2,247$; $p$-value<0.001), Hospice Knowledge Score $(F=20.15 ; d f=2,247 ; p$-value<0.001), Opinion about Provider of PC Score $(F=11.03$; $d f=2,247$; $p$-value<0.001) and Opinion Patient best setting to provide PC Score $(F=16.87$; $d f=2,247$; $p$-value $<0.001)$, Opinion about the best source of providing knowledge about PC Score $(F=$ $3.21 ; \mathrm{df}=2,247$; $\mathrm{p}$-value $=0.042$ ) were found significantly different for relationship with patient except Team Members of PC Score $(F=0.25 ; d f=2,247 ; p$-value = 0.776), Opinion about the Needs of Patients Suffering from an Incurable Disease Score $(F=3.01 ; d f=2,247 ; p$-value $=0.051)$ and Opinion that Palliative Care should be Offered to Everyone Suffering from an Incurable Disease Score $(F=1.58 ; \mathrm{df}=2,247$; $\mathrm{p}$-value $=0.207)$. (Table 3)

\section{Discussion}

The concept of palliative care or palliative care as a formal approach towards patients diagnosed with incurable and invariably progressive conditions, is relatively new to Pakistan, in the community and also among physicians. Just a handful of studies have been done on this concept so far in Pakistan. ${ }^{10,11,13}$ Aga Khan University Hospital recently set up a formal palliative care program consisting of a section of palliative medicine in the department of Oncology, with dedicated clinics and home based care services. At the same time an online course and workshops on palliative care are being offered to health care professionals. However, awareness in the community at large appears to be limited as it is new concept in Pakistan. All the respondents in this study were caring for patients with incurable and/or progressive conditions and were therefore, able to assess the needs of these patients in terms of symptom relief and providing comfort rather than futile attempts to cure the disease. They were also aware of the care and treatment being provided for their patient. whether in hospital, at home or in the outpatient clinics. The vast majority 223 (89\%) out of the total 250 study participants, were young adults upto the age of 50 years, whereas the remaining few were in the age range of 50 to 60 years. This is in keeping with the fact that carer's are more likely to be younger and able-bodied, as caring for patients on palliative care can be increasingly demanding as the patient's condition progresses. ${ }^{16}$ More than $50 \%$ of the carer's were male while over $85 \%$ of the study participants were at least graduates. A little over half of the carer's were close relatives of the patient, like wife, husband, sister or brother divided almost equally, while the remaining $54 \%$ of the carer's were nurses, nursing attendants or distant relatives. ${ }^{17,18}$ This is in keeping with the Pakistani cultural setting where close and sometimes even distant family members take over the role of carer/s when a relative becomes ill. In fact, many consider the opportunity of caring for a sick relative an honor and a privilege. (Table 1)

Page 5/11 
This broad, multi-contextual approach to PC requires a multidisciplinary group of trained and experienced professionals to provide care across all aspects of the four domains of palliative care. The PC approach stresses that the diagnosis of an incurable disease does not mean that nothing more can be done for the patient, on the contrary, a great deal can still be done to decrease and control physical and psychological symptoms, social issues and spiritual suffering of the patient. 2,3 It works in tandem with the 'patient centered approach' that is based on the principle that the patient should be given every opportunity to be involved in all aspects of care starting from complete information about the life-threatening condition to decision making about treatment options, unless the patient forgoes this right or defers it to a family member. ${ }^{19}$ In keeping with this, the majority of the respondents believed that the patient should be informed about the diagnosis of an incurable disease, whereas $19 \%$ were unsure and only $7.6 \%$ felt that the patient should not be told of the diagnosis. This response matches the findings reported in an earlier paper done in the community health center of the same hospital and international studies done in hospitals and the community. ${ }^{20,21}$ This finding should give more confidence to physicians to ask the patient if $\mathrm{s} / \mathrm{he}$ wants to know the diagnosis and discuss the management options. This is especially relevant when relatives insist that it should not be disclosed or discussed with the patient. ${ }^{18,19}$ Similarly, the majority of the respondents believed that patients should be encouraged to carry out routine activities and be facilitated to fulfill their wishes. This is in accordance with the palliative care approach that patients should be enabled to live normal lives and every effort should be made to fulfill their wishes to prevent helplessness and suffering. ${ }^{1}$ (Table 2)

The WHO definition of palliative care encompasses a holistic approach that enfolds the patient and family while focusing on improving quality of life and preventing suffering in terms of four broad domains; namely physical symptoms, psychological symptoms, social issues and concerns and the spiritual beliefs and practices of the patient. The goals of palliative care, therefore, are to ease the suffering of the patient and the family across all its domains, while remembering to stop and reassess at every step to ensure that futile treatments and false hope are avoided so that the patient and family do not suffer needlessly. This is in contrast to the focused medical approach, where the goal is to cure or treat the patient with the much broader palliative care approach covering multiple domains to ease the suffering of the patient and the family. Whereas PC can be provided in hospital, it can also be provided at home, in the clinic or hospice, which is a place where people with incurable conditions can pass their last months of life. ${ }^{22}$ Younger age had significant relationship with correct perceptions about PC, probably because this group was more likely to be educated and have greater exposure to electronic media and other sources of information, even if they had been less likely to have had any personal experience of caring for a relative suffering from a life-threatening disease. In contrast, the oldest age group also had a good understanding of this concept and the obvious explanation was their greater experience and therefore first-hand learning regarding this aspect of life, because by this stage in their lives they would have been more likely to have observed and/or been involved in the care of a family member or a friend suffering from a life-threatening disease. All age groups believed that an essential aspect of PC was fulfilling the needs of patients suffering from life threatening diseases. (Table 3)

Similarly, although the majority of the respondents were educated, participants educated to the secondary level at the time of data collection were younger and had better understanding of this concept in keeping with better knowledge in the youngest age group of carer's, whereas respondents with a higher level of education were older and had less knowledge.

That there was less variation in correct perceptions about these components across gender is understandable as both have equal opportunity to care for a dying relative, regardless of age and relationship with patient. However, males had a better understanding of the focus of palliative care whereas females had more correct understanding about where PC can be provided.

Children had significantly more correct information about PC compared to the patient or a spouse as a carer. This is predictable in that younger carer's have increased access to information technology like the internet and social media along with the education and skills to use it. This is probably because, although affected emotionally, children take on more responsibility in the practical and medical aspects of caring for their parents as patients, are more involved in 
discussions and management aspects with the medical team, and therefore actively seek information to enhance and improve the care of their affected parent, sparing the other parent of this difficult task. This can also be considered to be reflective of our cultural practices and the dearth of nursing homes and hospices so that children take on the responsibility of caring for parents as they age and/or when they are sick. ${ }^{13,14}$ Table 3

In terms of limitations, as this is a gradually expanding program, the carer's in the study sample may have acquired some information during the course of their interaction with the nurses and physicians, therefore the results should be generalized with caution to carer's receiving palliative care in settings without formal programs. As the large majority of the carer's were educated to at least the matric level, the opinions and attitudes of carer's without at least this level of education is not known.

\section{Conclusion}

Carer's of patients affected by life threatening diseases have a good understanding of the holistic PC approach, even though the discipline of PC does not exist in a formal or organized way in Pakistan. Younger age groups have the greatest understanding of this broad-based concept although older individuals have a reasonable level of knowledge also. Two foundational aspects showed a consistently good understanding and therefore correct knowledge across age groups, gender, education level, and relationship with the patient. Firstly, that palliative care should be offered to everyone suffering from an incurable disease and, secondly, that this approach encompasses not just physical, but also psychological and social needs of the patient, in addition to the needs of the family caring for the patient. It is important and essential to develop palliative care services while simultaneously making efforts to increase awareness about this holistic and multidisciplinary approach to patient care in both patients and carer's at a public health level. ${ }^{14,23}$

\section{Declarations}

\section{-Abbreviations}

- World Health Organization-WHO

- Palliative Care- PC

- AKUH-Agha Khan University and Hospital

\section{-Ethics approval and consent to participate}

This study was approved by the Aga Khan University Ethics Review Committee (Reference No. 3563-FM-ERC-13) Written consent was taken from each participant.

-Consent for publication Consent to publish the data gathered from the participants without referring to anyone or revealing the identity of any of the participants was taken from each participant All the authors have given consent for publication of this paper in BMC Palliative Medicine. - Availability of data and material All the data and material used in the conduct of this study is available for review.

- Competing interests None of the authors have any competing interests

- FundingThere was no funding for this study

- Authors' contributions The first 2 authors (SS, FQ), were directly involved in the conception, design, conduct, supervision, data collection and final review and approval of the paper. The third author (IA), did all the statistical analysis, wrote the 'Statistical Analysis' section and made the tables. The fourth author (KM) was involved in the design and conduct of the study. She also organized and supervised the data collection. All the authors reviewed and approved the final paper. - 
Acknowledgements We acknowledge with gratitude the support and facilitation provided by Zubair Masih RN, in the collection of the data.

- Authors' information.

$\circ$

- Sameena Shah was Assistant Professor in the Department of Family Medicine and had a joint appointment in the Palliative Medicine section of the department of Oncology at AKUH during the time this study was conducted and completed. She left soon after; but continued as visiting faculty in the department of Oncology for the next two years. She currently works and lives in Campbell River, BC, Canada.

- Faizan Qaisar was the home - based care physician in the Home Health Care Department of AKUH at the time of the conduct and completion of this study. He recently left to work in a different institution.

- Khairunnisa Mansoor was the head nurse of the Home Health Care Services of the AKUH at the time and has since joined the School of Nursing and Midwifery SONAM, AKUH and University, as Instructor.

- Mr. Iqbal Azam continues as Assistant Professor in the Department of Community and Health Sciences of the Aga Khan University.

\section{References}

1. https://www.who.int/cancer/palliative/defınition/en/. Accessed on 4th December, 2018 2. Higginson, Irene J., and Catherine J. Evans. "What is the evidence that palliative care teams improve outcomes for cancer patients and their families? " The Cancer Journal 16.5 (2010): 423-435 3. Higginson IJ, Costantini M. Dying with cancer, living well with advanced cancer. Eur J Cancer. 2008; 44:1414-1424) 4. World Health Organization. Global Action against Cancer. Geneva: World Health Organization/UICC; 2003). 5. Mularski, Richard A., et al. "Proposed quality measures for palliative care in the critically ill: A consensus from the Robert Wood Johnson Foundation Critical Care Workgroup." Critical care medicine 34.11 (2006): S404-S411.) 6. Benini F, Fabris M, Pace DS, et al. Awareness, understanding and attitudes of Italians regarding palliative care. Ann Ist Super Sanita 2011; 47(3): 253-259. 7. Center to Advance Palliative Care. Public opinion research on palliative care. A report based on research by public opinion strategies. New York: Center to Advance Palliative Care, 2011/ 8. Claxton-Oldfield S, Claxton-Oldfield J, Rishchynski G. Understanding of the term 'Palliative Care': a Canadian survey. Am J Hosp Palliat Care 2004; 21(2): 105-110 9. Hirai K, Kudo T, Akiyama M, et al. Public awareness, knowledge of availability, and readiness for cancer palliative care services: a population-based survey across four regions in Japan. J Palliat Med 2011; 14(8): 918-922 10. Abbas, S. Q., et al. "Awareness of palliative medicine among Pakistani doctors: a survey." JOURNAL-PAKISTAN MEDICAL ASSOCIATION 54.4 (2004): 195-198. 11. Singh T, Harding R. Palliative care in South Asia: a systematic review of the evidence for care models, interventions, and outcomes. BMC research notes. 2015 Dec;8(1):172. 12. Will Patients Want Hospice or Palliative Care if They Do Not Know What It Is? Matsuyama, Robin K. PhD; Balliet, Wendy PhD; Ingram, Kathleen PhD; Lyckholm, Laurie J. MD; Wilson-Genderson, Maureen PhD; Smith, Thomas J. MD Journal of Hospice \& Palliative Nursing: January-February 2011 - Volume 13 - Issue 1 - p 41-46 13. Shad A, Ashraf MS, Hafeez H. Development of palliative-care services in a developing country: Pakistan. Journal of pediatric hematology/oncology. 2011 Apr 1;33: S62-3. 14. Palliative Care in the Muslim-Majority Countries: The Need for More and Better Care. Contemporary and Innovative Practice in Palliative Care. Deena M. Aljawi1 and Joe B. Harford2. 2012. 15. http://www.merriam-webster.com/dictionary/caregiver Accessed on 7th January 2015. 16. Zarit SH. Family care and burden at the end of life. CMAJ 2004; 12:1811-2. 17. Morris SM, King C, Turner M, Payne S. Family carers providing support to a person dying in the home setting: a narrative literature review. Palliative medicine. 2015 Jun;29(6):487-95. 18. Ramirez A, Addington-Hall J, Richards M. ABC of palliative care. The carers. BMJ: British Medical Journal. 1998 Jan 17;316(7126):208. 19. Walczak A, Butow PN, Clayton JM, Tattersall MH, Davidson PM, Young J, Epstein RM. Discussing prognosis and end-of-life care in the final year of life: a randomised controlled trial of a nurse-led communication support programme for patients and caregivers. BMJ open. 2014 Jun 1;4(6):e005745. 20. Zafar W, Hafeez H, Jamshed A, Shah MA, Quader A, Yusuf MA. Preferences regarding disclosure of prognosis and end-of- life care: A survey of cancer patients 
with advanced disease in a lower-middle-income country. Palliative medicine. 2016 Jul;30(7):661-73. 21. Ishaque S, Saleem T, Khawaja FB, Qidwai W. Breaking bad news: exploring patient's perspective and expectations. Journal of the Pakistan Medical Association. 2010;60(5):407. 22. https://www.merriam-webster.com/dictionary/hospice. Accessed on 30th June 2019. 23. Ddungu, Henry. "Palliative care: what approaches are suitable in developing countries? " British journal of haematology 154.6 (2011): 728-735.

\section{Tables}

\section{Table 1}

Association of Different Socio-Demographic Distribution of Respondents with Correct Understanding of the Principles and Concept of Palliative Care (Crude and Adjusted Prevalence Ratios with 95\%)

\begin{tabular}{|c|c|c|c|c|}
\hline & & $\begin{array}{l}\text { Prevalence of Palliative Care } \\
\text { Knowledge } \\
(n=113 / 250)\end{array}$ & $\begin{array}{l}\text { Crude Prevalence Ratio } \\
(95 \% \mathrm{Cl})\end{array}$ & $\begin{array}{l}\text { Adjusted Prevalence } \\
\text { Ratio }(95 \% \mathrm{Cl})\end{array}$ \\
\hline \multirow{4}{*}{$\begin{array}{l}\text { Age Group (in } \\
\text { years) }\end{array}$} & $<30$ (Ref.) & $58.7 \%$ & 1 & 1 \\
\hline & $30-40$ & $62.3 \%$ & $1.06(0.70,1.61)$ & $0.74(0.42,1.28)$ \\
\hline & $40-50$ & $12.9 \%$ & $0.22(0.11,0.44)$ & $0.23(0.11,0.48)$ \\
\hline & $50-60$ & $44.4 \%$ & $0.76(0.40,1.42)$ & $0.66(0.34,1.31)$ \\
\hline \multirow[t]{2}{*}{ Gender } & Male & $46.4 \%$ & $1.07(0.73,1.56)$ & \\
\hline & $\begin{array}{c}\text { Female } \\
\text { (Ref.) }\end{array}$ & $43.4 \%$ & 1 & \\
\hline \multirow[t]{3}{*}{ Qualification } & $\begin{array}{c}\text { Up to } \\
\text { Secondary }\end{array}$ & $85.7 \%$ & $1.79(1.13,2.83)$ & $1.96(1.09,3.51)$ \\
\hline & Graduate & $31.1 \%$ & $0.65(0.42,1.00)$ & $0.49(0.29,0.84)$ \\
\hline & $\begin{array}{l}\text { Masters } \\
\text { (Ref.) }\end{array}$ & $47.9 \%$ & 1 & 1 \\
\hline \multirow[t]{3}{*}{$\begin{array}{l}\text { Relationship with } \\
\text { patient }\end{array}$} & $\begin{array}{l}\text { Self/Spouse } \\
\text { (Ref.) }\end{array}$ & $21.43 \%$ & 1 & 1 \\
\hline & Children & $46.48 \%$ & $2.17(1.04,4.53)$ & $1.01(0.44,2.34)$ \\
\hline & Others & $51.82 \%$ & $2.42(1.21,4.84)$ & $2.73(1.25,5.97)$ \\
\hline
\end{tabular}

Table 2

Frequency of Level of Agreement or Disagreement of Respondents with Core Concepts of Palliative Care $(n=250)$ 


\begin{tabular}{|c|c|c|}
\hline $\begin{array}{ll}\text { CORE CONCEPT } \\
\end{array}$ & RESPONSE & $\mathrm{N}(\%)$ \\
\hline \multirow[t]{6}{*}{ Person receiving palliative care should be allowed to carry out normal routine activities } & $\begin{array}{l}\text { Strongly } \\
\text { Agree }\end{array}$ & $\begin{array}{c}76 \\
(30.4 \%)\end{array}$ \\
\hline & Agree & $\begin{array}{c}76 \\
(30.4 \%)\end{array}$ \\
\hline & Disagree & $10(4.0 \%)$ \\
\hline & $\begin{array}{l}\text { Strongly } \\
\text { Disagree }\end{array}$ & $19(7.6 \%)$ \\
\hline & I Don't Know & $\begin{array}{c}69 \\
(27.6 \%)\end{array}$ \\
\hline & Total & 250 \\
\hline \multirow[t]{6}{*}{ Person receiving palliative care should be allowed to fulfill all his/her wishes } & $\begin{array}{l}\text { Strongly } \\
\text { Agree }\end{array}$ & $\begin{array}{c}130 \\
(52.0 \%)\end{array}$ \\
\hline & Agree & $\begin{array}{c}43 \\
(17.2 \%)\end{array}$ \\
\hline & Disagree & $11(4.4 \%)$ \\
\hline & $\begin{array}{l}\text { Strongly } \\
\text { Disagree }\end{array}$ & $17(6.8 \%)$ \\
\hline & I Don't Know & $\begin{array}{c}49 \\
(19.6 \%)\end{array}$ \\
\hline & Total & 250 \\
\hline \multirow[t]{6}{*}{$\begin{array}{l}\text { Person suffering from cancer should be given diagnosis or disease progress information } \\
\text { if s/he wants to know. }\end{array}$} & $\begin{array}{l}\text { Strongly } \\
\text { Agree }\end{array}$ & $\begin{array}{c}57 \\
(22.8 \%) \\
\end{array}$ \\
\hline & Agree & $\begin{array}{c}102 \\
(40.8 \%)\end{array}$ \\
\hline & Disagree & $24(9.6 \%)$ \\
\hline & $\begin{array}{l}\text { Strongly } \\
\text { Disagree }\end{array}$ & $19(7.6 \%)$ \\
\hline & I Don't Know & $\begin{array}{c}48 \\
(19.2 \%) \\
\end{array}$ \\
\hline & Total & 250 \\
\hline
\end{tabular}

Table 3

Score and Mean (SD) of Opinions about Different Aspects of Palliative Care by Socio-Demographic Characteristics 


\begin{tabular}{|c|c|c|c|c|c|c|c|c|c|c|c|}
\hline ics. & $\mathrm{n}$ & $\begin{array}{l}\text { Goals of } \\
\text { PC } \\
\text { Score } \\
\text { Mean (SD) }\end{array}$ & $\begin{array}{l}\text { Focus of } \\
\text { PC } \\
\text { Score } \\
\text { Mean } \\
\text { (SD) }\end{array}$ & $\begin{array}{c}\text { Team } \\
\text { Members } \\
\text { of PC } \\
\text { Score } \\
\text { Mean } \\
\text { (SD) }\end{array}$ & $\begin{array}{l}\text { Setting of } \\
\text { PC Score } \\
\text { Mean } \\
\text { (SD) }\end{array}$ & $\begin{array}{c}\text { Knowledge } \\
\text { about } \\
\text { Hospice } \\
\text { Score } \\
\text { Mean (SD) }\end{array}$ & $\begin{array}{l}\text { Provider of } \\
\text { PC Score } \\
\text { Mean (SD) }\end{array}$ & $\begin{array}{c}\text { Fulfilling } \\
\text { needs of } \\
\text { Patients } \\
\text { Suffering } \\
\text { from a } \\
\text { Terminal or } \\
\text { Incurable } \\
\text { Disease } \\
\text { Score } \\
\text { Mean (SD) }\end{array}$ & $\begin{array}{c}\text { Palliative } \\
\text { Care } \\
\text { should be } \\
\text { offered to } \\
\text { everyone } \\
\text { suffering } \\
\text { from a } \\
\text { life } \\
\text { threatening } \\
\text { disease } \\
\text { Score }\end{array}$ & $\begin{array}{l}\text { Best } \\
\text { setting } \\
\text { for } \\
\text { providing } \\
\text { PC } \\
\text { Score } \\
\text { Mean } \\
\text { (SD) }\end{array}$ & $\begin{array}{c}\text { The best } \\
\text { source of } \\
\text { obtaining } \\
\text { knowledge } \\
\text { about PC } \\
\text { Score } \\
\text { Mean (SD) }\end{array}$ \\
\hline
\end{tabular}

Mean (SD)

\begin{tabular}{|c|c|c|c|c|c|c|c|c|c|c|c|}
\hline & 250 & $1.37(0.97)$ & $\begin{array}{c}2.21 \\
(1.42)\end{array}$ & $\begin{array}{c}2.23 \\
(1.38)\end{array}$ & $\begin{array}{c}1.95 \\
(1.14)\end{array}$ & $1.17(1.06)$ & $1.34(1.78)$ & $1.41(0.75)$ & $4.62(4.15)$ & $\begin{array}{c}1.47 \\
(1.09)\end{array}$ & $2.41(1.83)$ \\
\hline & 92 & $1.80(0.76)$ & $\begin{array}{c}2.33 \\
(1.08)\end{array}$ & $\begin{array}{c}2.51 \\
(0.90)\end{array}$ & $\begin{array}{c}2.15 \\
(1.33)\end{array}$ & $1.32(1.33)$ & $1.85(1.92)$ & $1.41(0.84)$ & $4.53(3.48)$ & $\begin{array}{c}1.75 \\
(1.22)\end{array}$ & $2.59(2.30)$ \\
\hline & 61 & $1.34(0.96)$ & $\begin{array}{c}2.00 \\
(1.43) \\
\end{array}$ & $\begin{array}{c}1.07 \\
(1.17) \\
\end{array}$ & $\begin{array}{c}1.10 \\
(1.04) \\
\end{array}$ & $0.75(0.77)$ & $0.26(0.73)$ & $1.44(0.67)$ & $1.49(2.44)$ & $\begin{array}{c}0.98 \\
(1.02) \\
\end{array}$ & 1.75 (1.49) \\
\hline & 70 & $0.93(1.00)$ & $\begin{array}{c}1.66 \\
(1.59) \\
\end{array}$ & $\begin{array}{c}2.97 \\
(1.64) \\
\end{array}$ & $\begin{array}{c}2.29 \\
(0.57) \\
\end{array}$ & $1.23(0.94)$ & $1.29(1.96)$ & $1.36(0.76)$ & $5.71(4.65)$ & $\begin{array}{c}1.20 \\
(0.79) \\
\end{array}$ & $2.44(1.30)$ \\
\hline & 27 & $1.11(1.01)$ & $\begin{array}{c}3.74 \\
(0.71) \\
\end{array}$ & $\begin{array}{c}2.00 \\
(0.28) \\
\end{array}$ & $\begin{array}{c}2.30 \\
(0.82) \\
\end{array}$ & $1.44(0.58)$ & $2.15(1.29)$ & $1.48(0.58)$ & $9.15(1.98)$ & $\begin{array}{c}2.30 \\
(0.67) \\
\end{array}$ & $3.22(1.45)$ \\
\hline & 151 & $1.32(0.99)$ & $\begin{array}{c}2.50 \\
(1.43)\end{array}$ & $\begin{array}{c}2.36 \\
(1.41)\end{array}$ & $\begin{array}{c}1.79 \\
(1.04)\end{array}$ & $1.05(0.86)$ & $0.73(1.26)$ & $1.22(0.69)$ & $4.34(4.39)$ & $\begin{array}{c}1.36 \\
(0.97)\end{array}$ & $2.11(1.73)$ \\
\hline & 99 & $1.45(0.95)$ & $1.77(1.3)$ & $2.03(1.3)$ & $2.18(1.26)$ & $1.35(1.28)$ & $2.26(2.04)$ & $1.71(0.74)$ & $5.04(3.74)$ & $1.64(1.25)$ & $2.88(1.89)$ \\
\hline lary & 35 & $1.971(.38)$ & $2.66(.99)$ & $2.08(.44)$ & $1.97(.38)$ & $0.94(.48)$ & $3.05(2.04)$ & $1.89(0.323)$ & $7.05(2.04)$ & $2.25(.61)$ & $2.14(1.22)$ \\
\hline Juate & 119 & $1.21(1.19)$ & $1.32(1.36)$ & $2.57(1.75)$ & $2.08(1.18)$ & $1.51(1.22)$ & $1.100(1.66)$ & $1.61(0.71)$ & $5.30(4.37)$ & $1.33(1.19)$ & $2.75(1.8)$ \\
\hline e \& above & 96 & $1.35(1.37)$ & $3.12(2.21)$ & $1.85(2.23)$ & $1.77(1.95)$ & $0.82(1.17)$ & $1.00(1.34)$ & $0.99(0.703)$ & $2.88(4.62)$ & $1.34(1.47)$ & $2.08(2.41)$ \\
\hline ' & 42 & $0.90(0.79)$ & $2.93(1.04)$ & $2.12(0.88)$ & $2.83(0.69)$ & $0.81(0.94)$ & $1.62(1.36)$ & $1.17(0.66)$ & $4.48(4.44)$ & $1.88(0.80)$ & $3.00(1.63)$ \\
\hline & 71 & $1.62(0.62)$ & $2.76(1.20)$ & $2.31(0.95)$ & $1.72(1.13)$ & $0.69(0.60)$ & $2.03(1.97)$ & $1.41(0.96)$ & $5.35(3.83)$ & $1.89(1.33)$ & $2.48(2.23)$ \\
\hline & 137 & $1.39(1.12)$ & $1.71(1.43)$ & $2.23(1.66)$ & $1.80(1.14)$ & $1.53(1.14)$ & $0.89(1.65)$ & $1.49(0.63)$ & $4.28(4.21)$ & $1.12(0.93)$ & $2.20(1.62)$ \\
\hline
\end{tabular}

\section{Supplementary Files}

This is a list of supplementary files associated with this preprint. Click to download.

- STROBECHECKLISTDOCUMENT.docx 